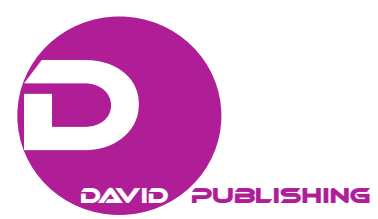

\title{
The Use of the ICTs in the Value Chain Processes and Their Impact on Organizational Performance
}

\author{
Zulema Córdova Ruiz, Sósima Carrillo, Loreto María Bravo Zanoguera, Jessica Lizbeth Cisneros Martínez \\ Autonomus University of Baja California, Mexicali, Mexico
}

\begin{abstract}
Companies are currently immersed in a process of competitiveness, which is increasingly more complicated to achieve differentiation that can guarantee you the preference of customers and consequently the success of the organization. It becomes partly crucial for the organization to be in the dynamics of the sector and market where it operates and wants its consolidation, because value systems become strategic elements that play a role as key factors of success in organizations seeking priority intend to increase their organizational performance. Given the above, this research seeks to get to identify strategic uses of information and communication technologies in the processes of the value chain in small commercial businesses in Mexicali, aiming to contribute to the improvement of the competitiveness of the same. It is in this sense that the technologies of information and communication have become a powerful tool that will allow them to be innovative, cost-effective and this will have an impact on the performance of the organization that will allow you to improve your service, interact with customers and suppliers, and above all more efficiently meet their own needs and organizational expectations. This research was exploratory and within the relevant findings, coming to the conclusion that it is necessary to focus more emphatically on the client; organizations have deficiencies in relation to the strategic use of ICTs to streamline their billing, manufacturing, distribution, and storage of your products, activities highlighting this if they don't have a reconsideration in this aspect, at the risk of offset in terms of its competitors which would mean ceasing to be option on the market, stressing that this not only will be a trigger factor in mature companies, but those who need to improve their service and that they will serve as input for the conduction of processes along the value chain. The research is exploratory in nature, as evidenced in the use of the ICTs focused on the management of the value chain and its relationship with different variables of such management, making that they are discovered behaviors on the structure of the value chain able to generate sustainable benefits and contribute to the improvement of the competitive position of the companies involved in this study.
\end{abstract}

Keywords: information technologies and communication, organizational performance, value chain, competitive, small businesses, improvement

Zulema Córdova Ruiz, master in Management, Faculty Administratives Sciences, Autonomus University of Baja California, Mexicali, Mexico.

Sósima Carrillo, Ph.D., Faculty Administratives Sciences, Autonomus University of Baja California, Mexicali, Mexico.

Loreto María Bravo Zanoguera, Ph.D., Faculty Administratives Sciences, Autonomus University of Baja California, Mexicali, Mexico.

Jessica Lizbeth Cisneros Martínez, master in Accounting, Faculty Administratives Sciences, Autonomus University of Baja California, Mexicali, Mexico.

Correspondence concerning this article should be addressed to Zulema Córdova Ruiz, Faculty Administratives Sciences, Autonomus University of Baja California, Mexicali, Mexico. 


\section{Introduction}

Today there are many challenges that organizations face; increased competitiveness and the phenomena of globalization, all these bring an environment of demand for companies looking to have more efficient responses, processes, and strategies that allow them to survive and consolidate in a changing world, in which the protagonist is the client, who takes more and more the power of negotiation and who at the end has the power to determine the success or failure of all business gear which is after manufacturing of a product or a service. Given that each time is more noticeable that the world is immersed in processes of continuous changes in business, such as economic growth, the increase of competition, among others. Being involved in these changes and the handling of information, a new economy based on technological and organizational transformation which focused on knowledge and information as a platform for production, this aimed at the achievement of competitiveness. These situations largely have made businesses focus and develop strategies that enable them to achieve competitive advantage by focusing on efforts to lower costs, productivity gains, and greater commitment in thier value chain, looking for this to reach one consolidation both nationally and internationally. And despite the efforts in many cases become even more complicated when there is evidence that production and marketing work does not end in the sale as such, but when the customer has accepted, has been satisfied with the product and it has paid. It is then when we can say that all this organizational tissue has fulfilled its mission. The objective pursued with this document is to determine what extent the companies' trade in the town of Mexicali B. C. comes making strategic use of the chain of value from the ICTs and as this affects organizational performance. The impact of them is widely recognized and is known that becomes a basic tool in the field of business around the world, but it is necessary that organizations try to build this application with due knowledge which will bring an impact generating value and fulfilling the expectations of the organization.

\section{Literature Review}

The management of information is a resource of value, to be part of an active process, and with presence in all the phases that make up the value chain, allowing it to gain the knowledge required to identify and determine the needs and priorities of customers, generate channels that allow you to meet them through the products or services required allowing to flow through the channels indicated, arriving for the creation of the same supplies and last are given the skills essential to the transformation (Oz \& Jones, 2008). Thus this activity includes the application of a sequence of steps such as the collection, organization, selection, synthesis, and distribution of information, after which the company will be able to create or identify heat creating alternatives for the client (Yazici, 2002). In this sense, where the use of the ICTs stands since through these service delivery of information by the company management is facilitated through activities such as data capture, database generation, business intelligence, portals, processing, storage, access, and analysis of information (Tiernan \& Peppard, 2004).

Given the term ICTs the set of computerized physical components (hardware) and programs (software), which, with communications networks, allow the automated treatment of information of events that affect each of generating value in the company activities. ICT, to improve the interaction between the internal activities of the company and between this, its suppliers, distributors, and customers, enhance the efficiency of the system (Joyanes, 2006). Highlight the fact that, in isolation, the ICTs do not have an impact, but once they are presented through an information system are they acquire the value that the potentiates, in this way, the 
relationship that may occur between them and value creation depends on the improvement of the processes inherent to the management of information which would allow the company to comply with the requirements and demands of the customer and thus gain efficiency in their performance to reach. Information management is a crucial process when it aims to create value through the use of internet (Marchand, 2000), due to the creation of value requires both information and knowledge as tools for achieving the objectives of the company (Tiernan \& Peppard, 2004). One of the tools used in the structural analysis of the organizations is the model of value chain, which is based on the study of the production process, highlighting the fact that entire production process begins with a raw material which undergoes a series of processes that is adding value, until you reach a final product that reaches the consumer. A "value chain" is comprised of a network of economic actors who focus their activities in the production of a product or service. A string usually involves from actors related with the production of raw materials to actors that transform and lead to consumer products or services. The value chain is defined as "the set of productive activities to develop a product or service, from design to production and delivery to the final consumer". A link in the chain is formed by a group of economic actors who perform similar activities, have similar value creation processes, and possess proprietary rights over a product or service in a State of defined value they transfer this product to their customers and receive inputs from the same suppliers. It is to recognize the fact that the majority of companies in the distribution chain using ICT, these are not used to enable business, and there is a widespread adoption of electronic tools which enhance the e-business giving added value to the marketing chain. A great deal of interest in supply chain management stems from the availability of information and the methods to analyze this information to reach meaningful results. As electronic business gains importance, new opportunities exist, and the wide spread use of internet is increasing the interest for the information technologies (Haag \& Stephen, 2010). There is a logical relationship between logistics and supply chain management, given that throughout history, goods that people wanted were not produced in the place where he wanted you to consume, or were not visible when the people wanted them to consume. Food and other useful or convenient goods were widely dispersed and only available in abundance at certain times of the year. The ancient could consume the goods in your immediate location or move to a preferred place, storing them for later use. However, as yet there were no transport and storage systems are well developed, the movement of goods was limited to what an individual could personally move, and storage of perishable goods was only possible for a short period of time. For its part the organizations have been present activities such as: inventory management, distribution of products, operations and service delivery, and products for consumers, which over time have been optimized, configured, and evolved to a more full term called logistics. From the years 60's, the changes are arising in the patterns of consumption, the increase is in demand; logistics was approached primarily as a physical distribution, where the focus of management was the total cost, the reported concept was: "Physical distribution is the set of activities related to the efficient movement of finished goods from the end of the production line to the consumer". For the 70's years, logistics was known as "the integration of two or more activities in order to plan, implement, and control the efficient flow of raw material, inventory in process, and finished goods from point of origin to point of consumption" (National Council of Physical Distribution Management, 1976). Later in the decade of the 1990s, the impact on the development of logistics was reflected in the inclusion of new elements to manage, such as information technology, service, and the management of strategic information (Cohen, Salomon, \& Nijkamp, 2002).

Turn to Ballou (2004), he says that logistics corresponds to all activities related to the transfer and storage of products which take place between the points of purchase and consumption points. Meanwhile, Carrasco 
(2000), appreciated the logistics as "the whole of activities that take place between the supply of raw materials and delivery of finished products to customers". From there the importance of valuing the subject of strategic logistics use, since it evaluates the most cost-effective methodology of distribution of products while maintaining the objectives of desired service levels. Technological strategies are strategic options. According to Davenport (2000), organizations must develop strategies that incorporate information technologies which contribute to the improvement of productivity and competitiveness. Strategy implementation of Customer Relationship Management (CRM), according to Bharadwaj (2000), is the process that allows you to redefine the strategic actions of an organization from the focus on the product to a customer as a person and your relationship with the organization-centred counselling. Strategy of application of Supply Chain Management (SCM), according to Kalakota and Robinson (1999), is the process that makes it possible to redirect the efforts of an organization related to the supply based on the value of relationships with suppliers. Application strategy of enterprise (resource planning ERP) systems, according to Davenport (2000), a business system is a package of computer programs that support most of the processes and factors related to an organization's information needs. Application of E-commerce strategy, in accordance with Pine (1999), with the development of this strategy enables its variety and the customization of the activities of the company in its business. Logistics revolves around creating value: value for the customers and suppliers of the company, and value for the shareholders of the company. The value in logistics is primarily expressed in terms of time and place. Products and services have no value unless they are in possession of customers when (time) and where (place) they want to consume it.

A good logistic direction displays each activity in the supply chain as a contribution to the process of adding value. If only you can add little value, then one can question whether such activity must exist. However, value is added when the customers prefer to pay more for a product or service than what it costs to put it in their hands. For several reasons, for many companies all around the world, the logistics has returned a process each time more important to the time of add value (Ballou, 2004). Using ICT tools to manage distribution and supply chain increases efficiency and certainty and waste reduction in the value chain and have a great impact on all market players. Large buyers in the supplier networks often use ICT tools to manage their producer networks. The ICT tools address record is keeping and monitoring the field agent activities, operations of procurement, tasks of credit and payment, and distribution of inputs, forecasting and determining productivity of the organization (Leenders \& Fearon, 2006).

\section{Research Method}

Sampieri (2010) methodology was the basis for the development of the investigative work. The research is exploratory in nature, as evidenced in the use of the ICTs focused on the management of the value chain and its relationship with different variables of such management, making that they are discovered behaviors on the structure of the value chain able to generate sustainable benefits and contribute to the improvement of the competitive position of the companies involved in this study.

The development of field work in 45 companies in the sector information was collected from trade of Mexicali, through structured interviews and application of questionnaires as tools for collecting information. Field research was aimed at high levels of the administration and management of the companies, with the intention of achieving better results for the fulfilment of the purposes of the investigation. The following steps were followed: search and compilation of existing publications on the subject in journals, references direct 
thematic catalogs; a compilation of sources from the search engines on the internet; location and selection of sources relating to the work, also became the investigative work through the directory of data companies, media written as journals and other publications. The information gathered was analyzed using the following approaches: qualitative data analysis, was subsequently defined a work plan to select relevant information and analyze it; the data were interpreted and sought to describe the different contexts that frame the development of research; continuing with the definition of patterns and is constructed arguments that contributed to the solution of the problem of the research.

And for the quantitative analysis of the data, is worked by selecting the method statistical type descriptive; they designed a questionnaire as instrument of measurement; and we used SPSS to analyze the resulting research variables.

\section{Results}

Strategic uses of the value chain in the trade sector are from the use of the technologies of information and communication (ICTs). First described briefly the factors of analysis used to analyze the processes of supply chain companies are analyzed under the use of ICTs: shopping-refers to the administrative rationality in the process of sourcing of supplies and products; also it comes to analyzing the relationship that you have with the supplier before, during and after; as well as the technology that used to carry out this process.

Inventories: Intends to analyze and identify how the company handles this essential part of the logistics; to thus recognize the importance of having a good management and control them. Distribution: Focuses on understanding and analyzes the process that takes place to get the product to the customer or consumer, taking into account the logistical efficiency according to the channels of distribution, times and points of delivery, and selected transport; as well as the information technology that supports these elements (Cooper, 1997).

Marketing: Refers to the analysis of every aspect of the marketing mix as they are product, price, promotion, and channels; identifying the technology used to manage them within the logistics system in turn. Service: Refers to the analysis of the bonding process with the customer before, during and after the sale (Bove, 2000). It is useful knowing of what way starting from this bonding and pro power, arise new opportunities for the development of other products and services related; and how they express an approach to the concept of Supply Chain Management.

Human talent: Refers to the structure of the staff within the company and to the analysis of skills and special requirements with which requires each person to develop his work both effectively and efficiently.

Logistics and strategy: This factor aims to identify and analyze if the companies defined strategies logistics, and of be so, that such interrelation exists between them strategies logistics and them corporate (Casanovas, 2001).

Hard and soft technology: This factor you want to understand and analyze the type of technology owned by the company and to what degree they contribute to the development of the logistics activities in a meaningful way; already is to support the operations business and/or taking of decisions.

Process integration: Seeks to identify the key points of interrelationships within the logistics process. For purposes of this investigation, it is important to analyze the existence of both internal and external integration of the logistics activities of the company and how they are supported with information technologies that help to make the processes more flexible, dynamic, and efficient changes presented in the environment (Gerald \& Anderson, 2000). 
Once specified above were obtained the following results of the research: in terms of the purchasing management, identifies that $75 \%$ of the companies analyzed, trying to make and maintain a good relationship with its suppliers, expressing interest in carrying out a better supply of its inputs, as shown in Figure 1. At the same time it shows that while companies focus on the customer, many do not determine their products in accordance with the opinion of the client, meaning that if you take into account of the needs and requirements of the customer but also for themselves. In the use of ICTs, it is a slight increase in the use of these for the mentioned activity, showing a little more of interest here to have a good logistics at least with their suppliers (35\% of the companies analyzed). On the situation of inventories, it reflected a weakness in terms of spaces, control, and the use of ICTs, since companies analyzed have not bothered to address this area of the company which is so important for logistics within the Organization; they have simply not seen that a good control for example would be a great benefit in time to think about expanding globally; and furthermore, this deficiency could get to consider a neck of bottle within the sector. Almost zero ICT management is then identified in $95 \%$ of the companies surveyed; being so necessary today to maintain a stock that does not generate higher costs, and of which only 14\% implement has invested in a platform that supports them in this activity, still predominantly use sheets control through excel and a low percentage do it manually, as shown in Figure 2.

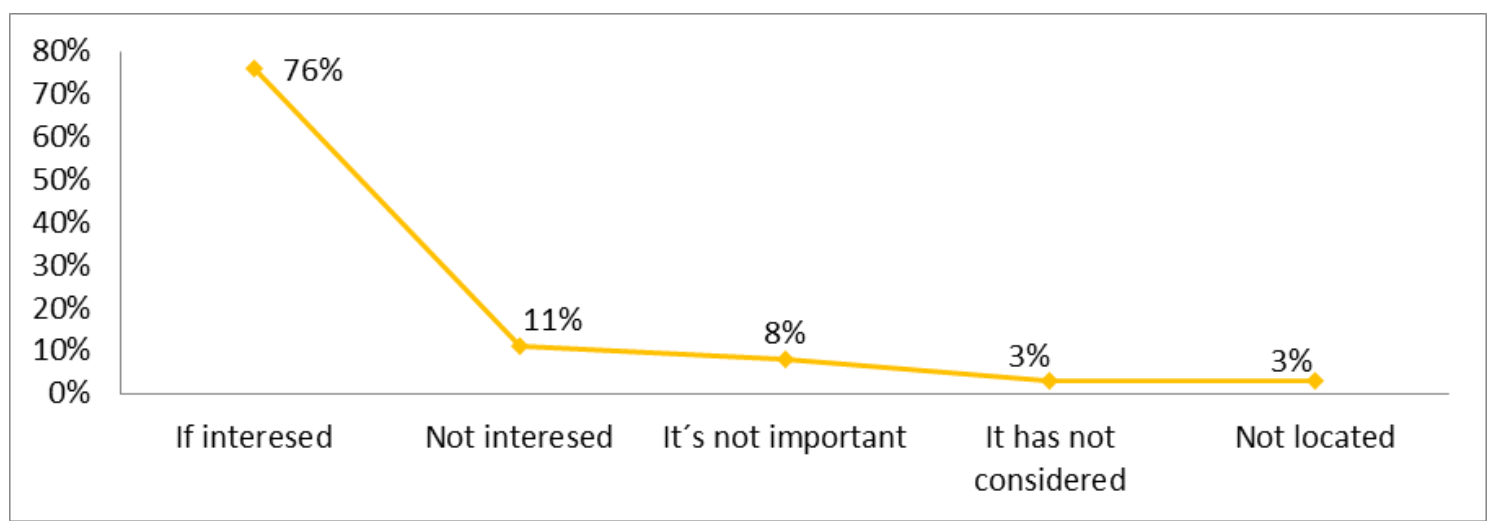

Figure 1. Relationship with suppliers.

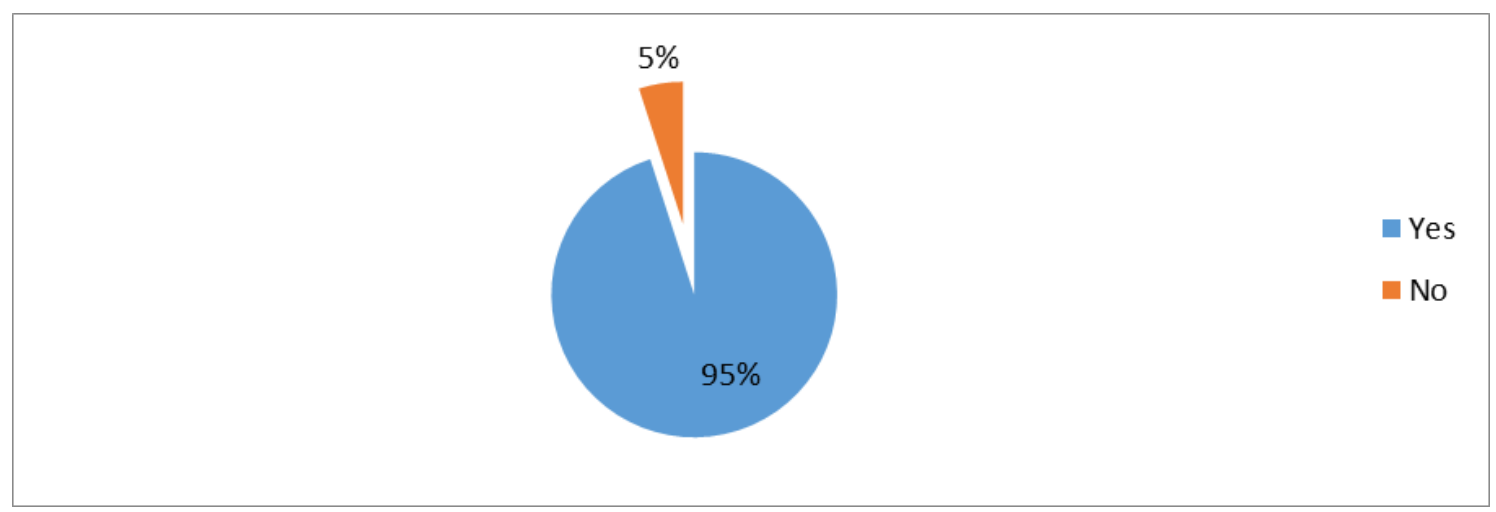

Figure 2. Inventory control system.

Addressing the distribution, one can see that after the analysis done to each point of the same, the companies under study in its entirety are not paying more importance in the excellent definition of channels of distribution and commercialization that are used at the time of reaching the customer or end-user; similarly they are not familiar to a large extent with the analysis of transport which will travel their products; they do not 
estimate efforts on these details at the time of selecting the best option. On the one hand they still recognize the importance of using ICT and e-commerce for the best use of this factor, and thus get to compete in a way that is stronger in the domestic market. On the subject of marketing, although $70 \%$ of the companies try to manage $100 \%$ of this activity, there are still many of them who do not have realized the importance of maintaining a good pricing strategies and have completely defined physical distribution channels; and yet are still being deficient in terms of the use of ICT for sales, and e-commerce within them. This should not go unnoticed since the world is governed by volatile consumer tastes, trends, and preferences, and when valued terms such as micro segmentation and the customer's identification are to obtain the greater profitability and strengthen a relationship of long term teaching (Kurt, 1993). However, employers' objectives of study don't pay heed to the dynamics that may have the subject of marketing. On the other hand, in terms of service, taking into account of the above analysis we can say that the companies analyzed; the vast majority being $90 \%$ of them, trying to satisfy the customer, but not all being $30 \%$ which have recognized the importance of carefully observing opportunities in the service they provide to give the customer a value added to the product and your experience with the company.

Also still being very weak the use of ICT and of their applications as trade electronic, marketing virtual, call centers, among others; leading to saying that your customer service can be too weak at the time to maintain customer loyalty. Stressing also the appearance on talent human within enterprises, should be relevant to the fact that companies come to life through people. This is why it is important to draw attention to employers, because it manifests that companies do not have much interest in training its staff in the formal sector, and if they do so in their field; however, when it comes to recruiting request that they already have the skills needed to fill the vacancy, leaving aside the creation of a close relationship with them in story to give them personal and professional growth. In addition, $68 \%$ of the companies did not display demanding to require special training to develop the main activities of the company. As regards to logistics and strategy are observed that their companies studied $82 \%$ of them not having the culture of planning strategic, i.e., could locate be inside a type of organizations reactive, since, only implement certain tools as is needed; regardless of an earlier study of themselves or of the industry where they move. Also it shows that their corporate strategies do not present greater alignment with strategies from each area of the logistics process, so that companies live in the present and do not see the importance of keeping in a changing future today. For the factor of ICTs, the panorama is not encouraging, since their companies considered that maintain satisfied to the customer with the promotion of their products, having certain benefits but not seen by no side some interest by responding to their expectations of the market global taken in has that not know how to use ICT in their processes logistics, and each one of them separately is not as efficient as they could be if they related each other supported the use of ICTs; and thus to respond faster and better to the market so demanding and sophisticated today. Attention is also the factor of integration of processes, and those companies of Mexicali in the sector commerce having not noticed the importance of having strong relationships with its customers and suppliers so that it can be more competitive within its sector; also according to Kalakota and Robbinson (2003) logistics processes are not fully integrated for glimpse of the bottlenecks of the same or opportunities that could be losing by not efficiently managing relations between these basic processes. To itself same is observed that the use of ICT for integrating the chain of value of each company analyzed, not represents greater benefit for the same; and not to consider it rather inefficient, simply do not use them due to ignorance of the typologies of ICTs in 56\% of them and ignorance of their operational benefits and mainly its strategic uses by $70 \%$. Also it managed to point out that there is a gap 
between corporate strategy and the strategy of catering, and it is a big gap between the two since the majority of the companies in the sector do not perform a strategic planning and supply chain planning much less, only a small percentage taking into account of this valuable alignment, but have not taken actions to integrate accounting for only $28 \%$ of the companies that were concerned and they have done something in the connection. Something else that is relevant was that despite the geographic position of the municipality of Mexicali a high number of companies don't think about internationalization, so have not assumed its true role, since before the proximity of new economic integrations, companies are not prepared for this. One of the main causes of the above is the lack of a strategic analysis (external and internal) business as their main source to be a step ahead of the current dynamics of the business environment and therefore not identified e-commerce as a way of extending the information between customers and companies that support it in its management. According to Koch (2002), he does not see it as a new market marketing channel, which allows to reduce costs, increase productivity, improve the quality of the service, and generate higher profits.

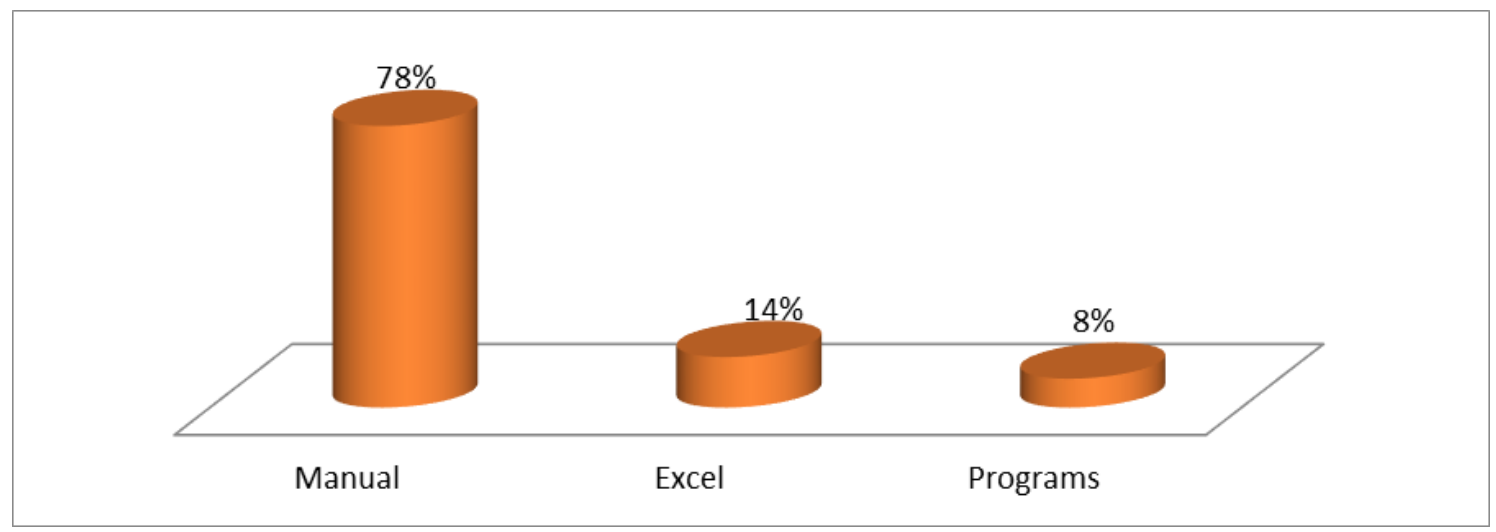

Figure 3. Inventory control management.

\section{Conclusion}

The issue of inside supply chain trade sector in the trade in Mexicali and Baja California, companies are in their early stages of evolution since even this term is not seen by employers as a way to become more competitive. Information is an important driver to any organization that serves as the element that creates and results in a coordinated effective supply chain. Therefore, it must be current, accurate, validated, and accessible in a timely and suitable manner, focused to the scope and intelligently managed by analytics. ICT tools support supply chain activities, proper planning, and management strategic decisions by a holistic visibility on; inventory (demands patterns, carrying costs), transportation (customer location, shipment sizes), facility (location, capacity, smart grid), and use design for recycle and reuse, limit waste and defects. An ICT tool (ERP, CRM) also allows to enhance the performance of the entire supply chain to make it less troublesome (Lysons \& Farrington, 2006). That is why we should work to implement efficient logistics processes, maintain distribution channels and minimum costs; without losing the due attention on the client and the achievement of their satisfaction, and to succeed one must add efforts in pursuit of the elimination of some business paradigms such as the fragmentation of areas of the company, hierarchy, the lack of cooperation with external customers, among others. These forms of thinking are converted in an obstacle for the change that presents each time more fast in the field business and more important is it must search the generate or devise a structure ideal of management, to have an approach to what the management of the chain of supply refers; seeing it as a new 
management tool to be more competitive. The use of the technologies of information and communication within a company becomes a key factor, since it is the basis to optimize the different activities within these. By that the companies of the sector trade must contemplate the investing, acquire, and use strategically them ICTs to supplement their needs and requirements; and thus meet the same objectives. It states so that the companies under study do a strategic use of supply chain already that do not recognize its importance, which implies that the supply chain is not a process of planned, detailed, integrated, and coordinated within the organizations analyzed. A consistent and successful way to get prosperous centers of utility for the companies in the sector, will be finding ways to influence supply chains through integration and collaboration, improving more and more products, reducing production and distribution cycles, analyzing the actual behavior of the demand seriously and altogether, and reducing the total cost of the value chains and their integration. The chain of value (Porter, 1985) has returned its base of any industry since it has last of a concept of distribution physical to one of logistics integrated to meet the needs of their customers. Its evolution has contributed to rethinking business models, facilitating better communication and coordination between the processes of the company.

\section{References}

Ballou, R. (2004). Logística. Administración de la cadena de suministro. Quinta ed. PEARSON EDUCACIÓN, México.

Bharadwaj, A. (2000). A resource-based perspective on information technology capability and firm performance: An empirical investigation. MIS Quarterly, 24.

Bove, M. (2000). From supply chain to value net. Journal of Business Strategy.

Carrasco, J. (2000). Evolución de los enfoques y conceptos de la logística. Madrid.

Casanovas, A., \& Cuatrecasas, L. (2001). Logística Empresarial. Gestión 2000, Barcelona.

Cohen, G., Salomon, I., \& Nijkamp, P. (2002). Information-communication technology (ICT) and transport: Does knowledge underpin policy? Telecommunications Policy, 26.

Cooper, D., \& Lambert. (1997). More than a new name for logistics. The International Journal of Logistics Management. The Ohio State University Press.

Council of Logistics Management. (1986). What is it all about? Oak Brook, IL.

Croxton, K., Garcia, Sastugue, S., \& Lambert, D. (2001). Supply chain management processes. The International Journal of Logistics Management, 12(2).

Davenport, T. (2000). Mision critical: Realizing the promise of enterprise systems (1st ed.). USA: Harvard Business School Press. Encuentro Internacional de Investigadores en Administración.

Oz, E., \& Jones, A. (2008). Management information systems (5th ed.). United Kingtdom by Cabrian Printers.

Gerald, V. P., \& David, L. A. (2000). Management information system: Solving business problems with information technolgy (2nd ed.). New York: McGraw-Hill Inc.

Haag, S., \& Cummings, M. (2010). Management information systems: For the information age (8th ed.). New York: McGraw-Hill Inc.

Joyanes, A. (2006). El poder del ciberespacio. El español de internet y de las innovaciones tecnológicas. ¿Un nuevo lenguaje técnico frente al inglés? ISBN: 84-8319-284-5

Kalakota, R., \& Robinson, M. (2003). E-business 2.0: Roadmap for success (2nd ed.). Addison-Wesley.

Koch, C. (2002). The ABCs of supply chain management. Supply Chain Management Research Center. CIO Magazine.

Kurt Salmon Asociates, Inc. (1993). Efficient consumer response: Enhancing consumer value in the grocery industry. Washington DC: Food Marketing Institute.

Leenders, R. M, \& Fearon, E. H. (1993). Purchasing and materials management (13th ed). Irwin, Chicago.

Lysons, K., \& Farrington. (2006). Purchasing and supply chain management (6th ed). London: Prentice-Hall.

Marchand, D. A. (2000). Competing with information: A manager's guide to creating business value with information content. National Council of Physical Distribution Management (1976).

Porter, M. (1985). Ventaja Competitiva: Crear y Mantener un Desempeño Superior (1st ed.) USA: Harvard Business School Press. 
Sampieri, R. (1998). Metodología de la Investigación (2nd ed). México: McGraw.

Sampieri, F. (2010). Metodología de la Investigación (5th ed). México: McGraw.

Tiernan, C., \& Peppard, J. (2004). Information technology: Of value or a vulture? European Management Journal, 22(6).

Yazici, H. J. (2002). The role of communication in organizational change: An empirical investigation. Information and Management, 39, 539-52. 